\title{
Measurements of $\mathrm{NH}_{3}$ and $\mathrm{CO}_{2}$ with distributed-feedback diode lasers near $2.0 \mu \mathrm{m}$ in bioreactor vent gases
}

\author{
Michael E. Webber, Ricardo Claps, Florian V. Englich, Frank K. Tittel, Jay B. Jeffries, \\ and Ronald K. Hanson
}

\begin{abstract}
Measurements of $\mathrm{NH}_{3}$ and $\mathrm{CO}_{2}$ were made in bioreactor vent gases with distributed-feedback diode-laser sensors operating near $2 \mu \mathrm{m}$. Calculated spectra of $\mathrm{NH}_{3}$ and $\mathrm{CO}_{2}$ were used to determine the optimum transitions for interrogating with an absorption sensor. For ammonia, a strong and isolated absorption transition at $5016.977 \mathrm{~cm}^{-1}$ was selected for trace gas monitoring. For $\mathrm{CO}_{2}$, an isolated transition at $5007.787 \mathrm{~cm}^{-1}$ was selected to measure widely varying concentrations [500 parts per million (ppm) to $10 \%$ ], with sufficient signal for low mole fractions and without being optically thick for high mole fractions. Using direct absorption and a 36-m total path-length multipass flow-through cell, we achieved a minimum detectivity of $0.25 \mathrm{ppm}$ for $\mathrm{NH}_{3}$ and $40 \mathrm{ppm}$ for $\mathrm{CO}_{2}$. We report on the quasi-continuous field measurements of $\mathrm{NH}_{3}$ and $\mathrm{CO}_{2}$ concentration in bioreactor vent gases that were recorded at NASA Johnson Space Center with a portable and automated sensor system over a 45-h data collection window. (C) 2001 Optical Society of America

OCIS codes: $\quad 300.6260,300.6390,300.1030,300.6340$.
\end{abstract}

\section{Introduction}

The Crew and Thermal Systems Division at NASA Johnson Space Center (JSC) in Houston, Texas, has been developing an advanced water recovery system (WRS) for implementation aboard manned spacecraft. ${ }^{1}$ The WRS will be used to convert wastewater into potable drinking water and includes a biological waste processor (or bioreactor) that removes carbon content from wastewater. NASA is motivated to develop a spaceboard water treatment system because of the closed nature of spacecraft, which prevents astronauts from simply discarding waste out of the

When this research was performed, M. E. Webber, J. B. Jeffries (jeffries@navier.stanford.edu), and R. K. Hanson were with the High Temperature Gasdynamics Laboratory, Department of Mechanical Engineering, Stanford University, Stanford, California 94305-3032. M. E. Webber is now with Pranalytica, Incorporated, 1101 Colorado Avenue, Santa Monica, California 90401. When this research was performed, R. Claps, F. V. Englich, and F. K. Tittel were with the Laser Science Group, Rice Quantum Institute, Department of Electrical and Computer Engineering, Rice University, Houston, Texas 77251-1892. R. Claps is now with Radiant Photonics, Incorporated, 1908 Kramer Lane, Building B, Austin, Texas 78758.

Received 4 December 2000; revised manuscript received 17 April 2001.

0003-6935/01/244395-09\$15.00/0

(C) 2001 Optical Society of America spacecraft, and because of the expense associated with shipping fresh drinking water to the astronauts.

The bioreactor is currently in ground tests for development and optimization, during which NASA is interested in monitoring the $\mathrm{NH}_{3}$ and $\mathrm{CO}_{2}$ content in the bioreactor's vent gases. ${ }^{2}$ In this paper we describe the design of a diode-laser sensor used to record gas-phase $\mathrm{NH}_{3}$ and $\mathrm{CO}_{2}$ mole fractions, explain the motivation to measure these species, and present results from demonstration field measurements at NASA JSC over a multiday data collection window. The sensor used direct absorption and a 36-m total path-length multipass flow-through cell to interrogate the $v_{3}+v_{4}$ and $v_{1}+2 v_{2}+v_{3}$ combination bands at $2 \mu \mathrm{m}$ of $\mathrm{NH}_{3}$ and $\mathrm{CO}_{2}$, respectively. The minimum detectivity that we achieved using this sensor was 0.25 parts per million (ppm) for $\mathrm{NH}_{3}$ and 40 ppm for $\mathrm{CO}_{2}$, which is suitable for the expected vent gas concentrations.

\section{Theory}

The fundamental theory that governs absorption spectroscopy for narrow-linewidth radiation sources is embodied in the Beer-Lambert law, Eq. (1), and is described thoroughly in Ref. 3. The ratio of the transmitted intensity $I_{t}$ and initial (reference) intensity $I_{0}$ of laser radiation through an absorbing medium at a particular frequency is exponentially related to the transition line strength 
$S_{i}\left[\mathrm{~cm}^{-1} /(\right.$ atm $\left.\mathrm{cm})\right]$, line-shape function $\phi(\mathrm{cm})$, total pressure $P(\mathrm{~atm})$, mole fraction of the absorbing species $x_{j}$, and the path length $L(\mathrm{~cm})$ :

$$
\frac{I_{t}}{I_{0}}=\exp \left(-S_{i} \phi P x_{j} L\right) .
$$

The normalized line-shape function describes the effects of thermal motion (Doppler broadening) and intermolecular collisions (collisional or pressure broadening), which have Gaussian and Lorentzian line shapes, respectively. Ammonia and carbon dioxide absorption transitions at room temperature and subatmospheric pressure will have line shapes that are described by the Voigt function, which is a convolution of the Gaussian and Lorentzian functions. Because the line shape is normalized, if we wavelength tune the laser across an isolated absorption transition and integrate the area under the line shape, we obviate the need for detailed broadening or line-shape analysis.

The line strength as a function of temperature for a particular transition $i$ is governed by its line strength $S_{i}$ at a reference temperature $T_{0}$, the partition function $Q(T)$ of the absorbing molecule $\left(\mathrm{CO}_{2}\right.$ or $\mathrm{NH}_{3}$ ), the frequency of the transition $\nu_{0, i}$, and the lower-state energy of the transition $E_{i}{ }^{\prime \prime}$. This relationship is given by

$$
\begin{aligned}
S_{i}(T)= & S_{i}\left(T_{0}\right) \frac{Q\left(T_{0}\right)}{Q(T)}\left(\frac{T_{0}}{T}\right) \exp \left[-\frac{h c E_{i}^{\prime \prime}}{k}\left(\frac{1}{T}-\frac{1}{T_{0}}\right)\right] \\
& \times\left[1-\exp \left(\frac{-h c v_{0, i}}{k T}\right)\right] \\
& \times\left[1-\exp \left(\frac{-h c v_{0, i}}{k T_{0}}\right)\right]^{-1} .
\end{aligned}
$$

The partition functions for $\mathrm{NH}_{3}$ and $\mathrm{CO}_{2}$ are available in Refs. 4 and 5, respectively.

\section{Line Selection}

The design of a laser-based sensor for $\mathrm{NH}_{3}$ and $\mathrm{CO}_{2}$ in the bioreactor vent gases requires careful selection of optimum transitions that offer adequate sensitivity over the range of expected populations and isolation from potential interfering species. The main constituents of the bioreactor vent gases include $\mathrm{N}_{2}$, less than $10 \mathrm{ppm}$ of $\mathrm{NH}_{3}, 500 \mathrm{ppm}$ to $10 \% \mathrm{CO}_{2}$, and saturated water vapor. For trace $\mathrm{NH}_{3}$ detection, the strongest available and isolated transitions need to be selected. For $\mathrm{CO}_{2}$ detection, an isolated transition needs to be employed that offers sufficient signal at the low concentration end (500 ppm), yet is not optically thick for high concentrations $(>5 \%)$. The $\mathrm{NH}_{3}$ transitions need to be isolated from saturated water vapor and $\mathrm{CO}_{2}$, whereas $\mathrm{CO}_{2}$ transitions need to be isolated from saturated water vapor and $\mathrm{NH}_{3}$.

Figure 1 shows the line strengths of $\mathrm{NH}_{3}, \mathrm{H}_{2} \mathrm{O}$, and $\mathrm{CO}_{2}$ in the near infrared between 1.4 and $2.5 \mu \mathrm{m} .^{5-7}$ The line strengths in the $2-\mu \mathrm{m}$ region are approximately 100 times stronger for $\mathrm{CO}_{2}$ as compared with

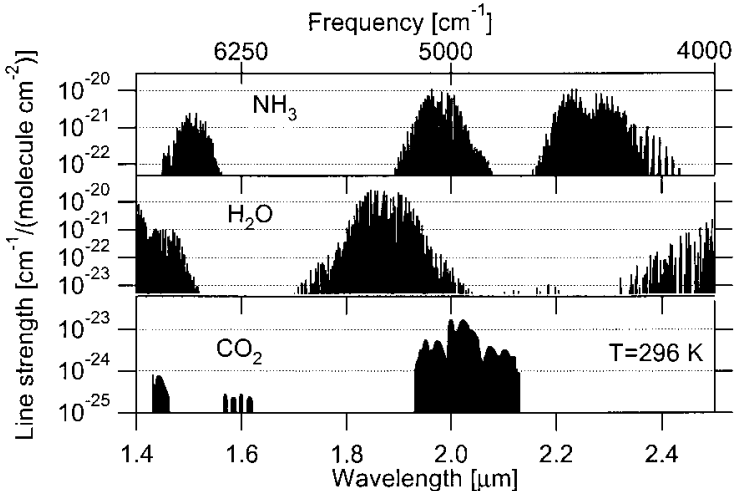

Fig. 1. Calculated $\mathrm{NH}_{3}, \mathrm{H}_{2} \mathrm{O}$, and $\mathrm{CO}_{2}$ line strengths in the near infrared at $296 \mathrm{~K}^{5-7}$

the telecommunication wavelengths near $1.6 \mu \mathrm{m}$, and the $\mathrm{NH}_{3}$ line strengths at $2 \mu \mathrm{m}$ are approximately three times stronger than at $1.5 \mu \mathrm{m}$. Thus, use of diode lasers at the longer wavelengths offers the opportunity for more sensitive detection. Figure 2 shows the survey spectra of $\mathrm{NH}_{3}$ recorded with an external-cavity diode laser from 4900 to $5100 \mathrm{~cm}^{-1}$ $(1960-2040 \mathrm{~nm})$. The survey was used to qualitatively confirm the transition strengths and locations that are listed in the HITRAN96 database. The $\mathrm{CO}_{2}$ bands near $2 \mu \mathrm{m}$ were confirmed with previously published survey spectra. ${ }^{8}$

Calculated spectra of $\mathrm{NH}_{3}, \mathrm{CO}_{2}$, and $\mathrm{H}_{2} \mathrm{O}$ were used to select optimum transitions for isolated species detection. The best choice for sensitive $\mathrm{NH}_{3}$ monitoring in the presence of $\mathrm{CO}_{2}$ and $\mathrm{H}_{2} \mathrm{O}$ is the ${ }^{P} P_{3}(3)_{s}$ transition at $5016.977 \mathrm{~cm}^{-1}$. This transition is part of a doublet that offers the third strongest absorption in the measured survey spectra at $2 \mu \mathrm{m}$, but as Fig. 3 illustrates, is also isolated from $\mathrm{H}_{2} \mathrm{O}$ interference. The selected feature does have some overlap in the wings from the $P(32)$ transition of $\mathrm{CO}_{2}$ for large $\mathrm{CO}_{2}$ concentrations. This slight overlap enables the opportunity for a single scan to yield measurements of $\mathrm{NH}_{3}$ and $\mathrm{CO}_{2}$ for cases during which the $\mathrm{CO}_{2}$ concentration is greater than approximately $3 \%$.

For bioreactor gas samples containing smaller

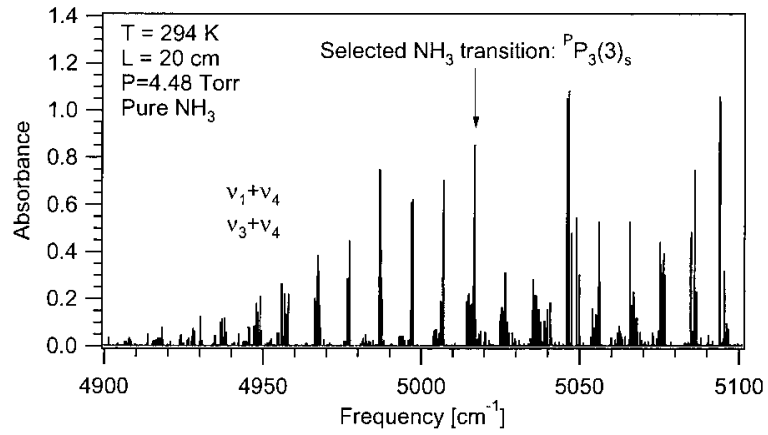

Fig. 2. Measured survey spectra of pure $\mathrm{NH}_{3}$ near $2 \mu \mathrm{m}$ recorded with an external-cavity diode laser. The transition that was selected for bioreactor monitoring is indicated on the plot. 


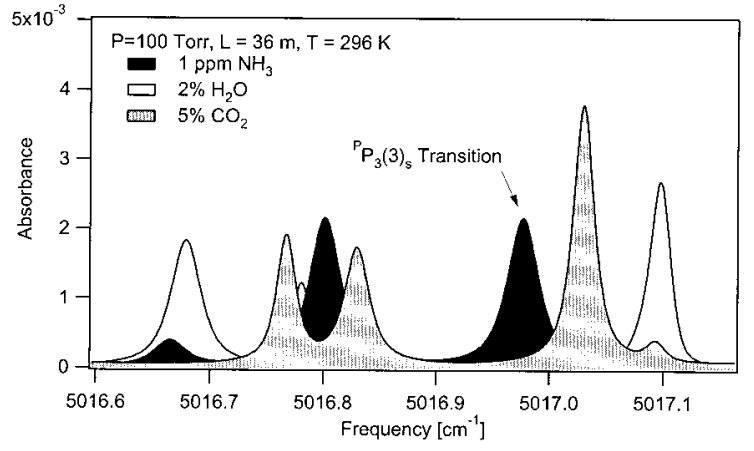

Fig. 3. Calculated spectra near $5017 \mathrm{~cm}^{-1}$ for $1 \mathrm{ppm} \mathrm{NH}, 5 \%$ $\mathrm{CO}_{2}$, and $2 \% \mathrm{H}_{2} \mathrm{O}$ (standard humidity).

amounts of $\mathrm{CO}_{2}(<3 \%)$, the isolated $R(50)$ transition at $5007.787 \mathrm{~cm}^{-1}$ has a line strength suitable for detection with direct absorption. Figure 4 shows the calculated peak absorption for the $R(50)$ and $P(32)$ transitions at 5007.787 and $5017.030 \mathrm{~cm}^{-1}$, respectively, for typical conditions in multipass sampling cells $(L=36 \mathrm{~m}, P=100$ Torr, $T=296 \mathrm{~K})$ and for the range of expected $\mathrm{CO}_{2}$ concentrations in the bioreactor gas samples (500 ppm to $10 \%)$. By operating at different diode temperatures, we can access both transitions with a single laser. The peak absorption of the $P(32)$ line varies from approximately $0.3 \%$ at $X_{\mathrm{CO}_{2}}=3 \%$ up to $0.8 \%$ for $X_{\mathrm{CO}_{2}}=10 \%$. The peak absorption for the $R(50)$ transition varies from roughly $1 \%$ at $X_{\mathrm{CO}_{2}}=500 \mathrm{ppm}$ to $80 \%$ at $X_{\mathrm{CO}_{2}}=8 \%$; thus it offers the dynamic range necessary to track the varying concentrations up to $8 \%$ without being optically thick at the high end nor undetectable at the low end. Moreover, the transition is isolated from $\mathrm{H}_{2} \mathrm{O}$ and $\mathrm{NH}_{3}$ and offers the added simplicity that it can be approximated with a single Voigt profile, in contrast with many other transitions of $\mathrm{CO}_{2}$ in the $2-\mu \mathrm{m}$ band that overlap with ${ }^{13} \mathrm{CO}_{2}$ transitions and thus require multi-Voigt curve fits.

Absorption from a flowing gas mixture of $9 \mathrm{ppm}$ $\mathrm{NH}_{3}, 74 \% \quad \mathrm{CO}_{2}$, and a balance of $\mathrm{N}_{2}$ through a 3600 -cm multipass cell was measured with a single sweep of the laser from 5016.7 to $5017.1 \mathrm{~cm}^{-1}$ (see Fig. 5). The absorption spectra show five clear fea-

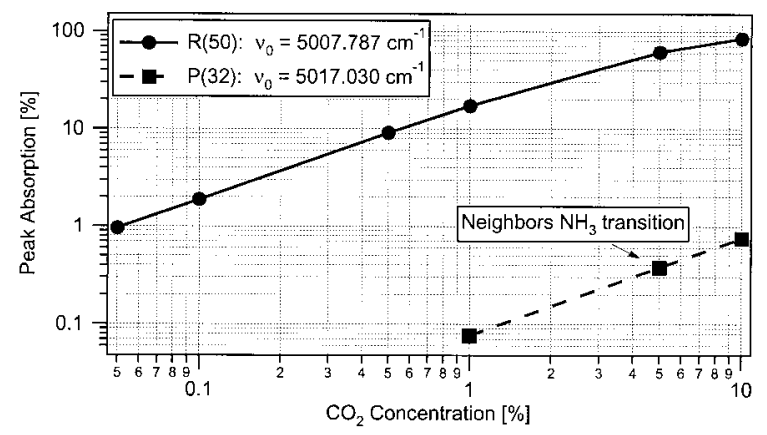

Fig. 4. Calculated peak absorption for the $\mathrm{CO}_{2} R(50)$ feature at $5007.787 \mathrm{~cm}^{-1}$ and the $\mathrm{CO}_{2} P(32)$ transition at $5017.030 \mathrm{~cm}^{-1}$ versus concentration for the range $500 \mathrm{ppm}$ to $10 \%$ by use of typical sampling cell conditions (296 K, 100 Torr, 36 m).

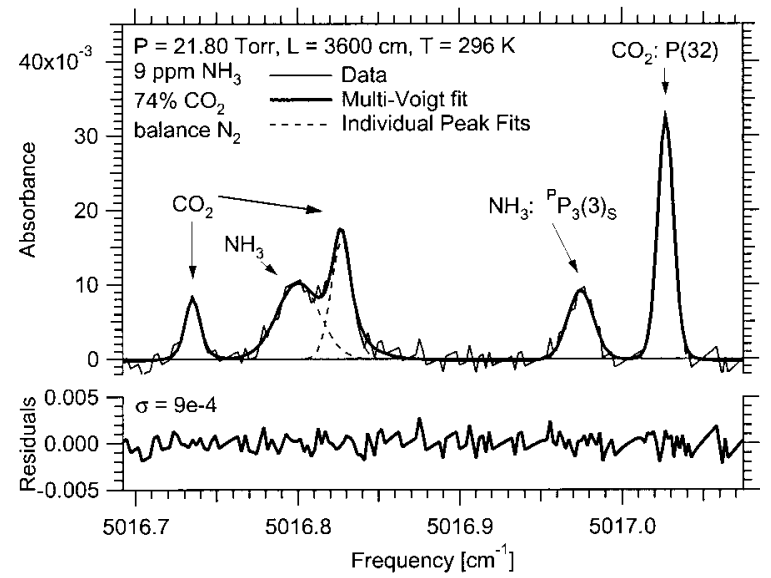

Fig. 5. Demonstration measurements with a distributed feedback diode laser confirm that the $\mathrm{NH}_{3}$ transition at $5016.977 \mathrm{~cm}^{-1}$ is isolated from interfering $\mathrm{H}_{2} \mathrm{O}$ and $\mathrm{CO}_{2}$ absorption. The capacity to measure $\mathrm{NH}_{3}$ and $\mathrm{CO}_{2}$ simultaneously with a single laser sweep is also evident.

tures, two from the ${ }^{P} P_{3}(3) \mathrm{NH}_{3}$ doublet and three from neighboring $\mathrm{CO}_{2}$ lines. These measurements confirm the following: (1) the $\mathrm{NH}_{3}$ transition at $5016.802 \mathrm{~cm}^{-1}$ suffers from significant $\mathrm{CO}_{2}$ overlap, (2) the $\mathrm{NH}_{3}$ transition at $5016.977 \mathrm{~cm}^{-1}$ is isolated from $\mathrm{CO}_{2}$ interference at reduced pressures, and (3) a single scan can be used to measure trace $\mathrm{NH}_{3}$ and major populations $(>3 \%)$ of $\mathrm{CO}_{2}$ simultaneously.

\section{Spectroscopic Results}

Before an absorption sensor could be implemented, the line positions, lower-state energies, and line strengths of the selected transitions need to be known accurately. We determined the line strengths at a given temperature by integrating the area of Voigt fits to each measured absorption transition for a range of pressures between 20 and 150 Torr for $\mathrm{CO}_{2}$ and 1 and 10 Torr for $\mathrm{NH}_{3}$. The integrated absorbance of an individual transition increases linearly with pressure; thus we can determine the line strength by performing a linear fit on the integrated areas at various pressures and using the slope to calculate the line strength. Because zero pressure corresponds to zero absorbance, the linear fit was constrained to pass through the origin.

Using the process described above, we determined the line strengths for the five $\mathrm{NH}_{3}$ features near 5017 $\mathrm{cm}^{-1}$ because these transitions blend into one feature even at subatmospheric pressure. A high-resolution image of the five absorption features measured in a static cell is depicted in Fig. 6. Four of the five transitions in Fig. 6 were assigned to the ${ }^{P} P_{1}(2)$ and ${ }^{P} P_{3}(3)$ doublets, and the fifth feature was assigned as the ${ }^{R} Q_{3}(7)_{s}$ transition; all are from the $v_{3}+v_{4}$ perpendicular combination band. ${ }^{5,9-11}$

The results from these line-strength measurements are summarized in Table 1 along with published values. The total uncertainty for the individual line-strength measurements was esti- 


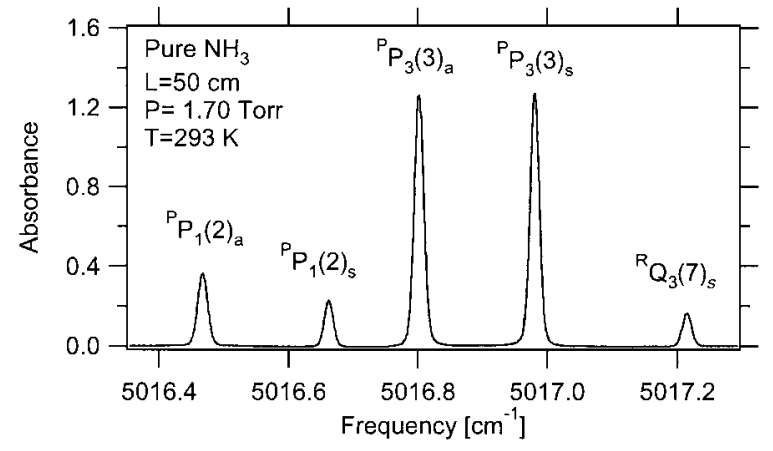

Fig. 6. High-resolution measurement of the $\mathrm{NH}_{3}$ transitions near $5017 \mathrm{~cm}^{-1}$.

mated to be approximately $3 \%$, resulting from measurement uncertainties of $1 \%$ in the total pressure and $2 \%$ in the area under each Voigt profile. The measured line strengths agreed with the published values at best within $\pm 0.9 \%$ for the transition at $5016.471 \mathrm{~cm}^{-1}$ and at worst within $\pm 3.4 \%$ for the transition at $5016.665 \mathrm{~cm}^{-1}$, both of which are well within the combined uncertainty from the measurements $( \pm 3 \%)$ and published values $(5-10 \%)$. Because these high-resolution measurements had smaller uncertainties than those listed in HITRAN96, we consider the measured values to be an improvement. The measured line strengths for the $\mathrm{CO}_{2}$ transition at $5007.787 \mathrm{~cm}^{-1}$ were previously published $^{12}$ and are listed in Table 2.

Measurements of line strength at various temperatures are shown in Fig. 7. The individual data points are overlaid with a solid curve that indicates predicted values based on the measured room-

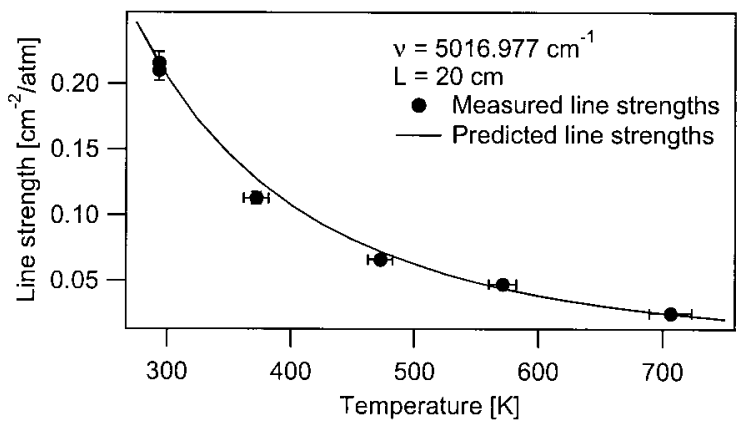

Fig. 7. Measured line strengths at various temperatures for the ${ }^{P} P_{3}(3)_{s} \mathrm{NH}_{3}$ feature at $5016.977 \mathrm{~cm}^{-1}$ overlaid with predicted values.

temperature value, published lower-state energy, and ammonia's partition function. The measured and predicted values agree within the measurement uncertainty and thereby confirm the line assignment and lower-state energy of this particular transition. The same agreement was determined for the other four features near $5017 \mathrm{~cm}^{-1}$. Note that all the measured line positions agreed with HITRAN96 values within the experimental uncertainty.

Using the measured line strengths, published lower-state energy, and published broadening coefficients, we predicted the minimum detectable mole fraction for the feature at $5016.977 \mathrm{~cm}^{-1}$ for varying pressures at $296 \mathrm{~K}$ (see Fig. 8). As the graph reveals, 100 Torr is the optimum pressure for sensitive detection. At higher pressures the $\mathrm{NH}_{3}$ population increases and the neighboring lines become blended, but the peak signal remains roughly the same, so higher pressures do not offer increased ability to dis-

Table 1. Comparison of Measured and Published Parameters for the Ammonia Transitions near $5017 \mathrm{~cm}^{-1}(1993 \mathrm{~nm})$

\begin{tabular}{ccccccccccccc}
\hline$v_{0}{ }^{a}$ & Transition $^{b}$ & $J^{\prime c}$ & $K^{\prime c}$ & $J^{\prime \prime d}$ & $K^{\prime \prime d}$ & $\sigma^{e}$ & $E^{\prime \prime f}$ & $S_{0, H}{ }^{g}$ & $S_{0, M}{ }^{* h}$ & $S_{0, M}{ }^{i}$ & $\sigma_{S}{ }^{j}$ & $\Delta S_{0}{ }^{k}$ \\
\hline 5016.471 & ${ }^{P} P_{1}(2)_{a}$ & 1 & 0 & 2 & 1 & $a$ & 56.7 & 0.0649 & 2.59 & 0.0643 & 0.0003 & -0.9 \\
5016.665 & ${ }^{P} P_{1}(2)_{s}$ & 1 & 0 & 2 & 1 & $s$ & 55.9 & 0.0381 & 1.48 & 0.0368 & 0.0003 & -3.4 \\
5016.802 & ${ }^{P} P_{3}(3)_{a}$ & 2 & 2 & 3 & 3 & $a$ & 86.7 & 0.2227 & 8.81 & 0.2185 & 0.0013 & -1.9 \\
5016.977 & ${ }^{P} P_{3}(3)_{s}$ & 2 & 2 & 3 & 3 & $s$ & 86.9 & 0.2227 & 8.71 & 0.2160 & 0.0007 & -3.0 \\
5017.211 & ${ }^{R} Q_{3}(7)_{s}$ & 7 & 4 & 7 & 3 & $s$ & 521.6 & 0.0271 & 1.06 & 0.0263 & 0.0002 & -2.8 \\
\hline
\end{tabular}

${ }^{a}$ Line center from HITRAN96 $\left(\mathrm{cm}^{-1}\right)$.

${ }^{b}$ Standard spectroscopic transition notation: ${ }^{\Delta K} \Delta J_{K^{\prime \prime}}\left(J^{\prime \prime}\right)_{\sigma}$.

${ }^{c}$ Upper-state symmetric top rotational quantum numbers.

${ }^{d}$ Lower-state symmetric top rotational quantum numbers.

eTransition symmetry: symmetric $(s)$ or asymmetric $(a)$.

${ }^{f}$ Lower-state energy $\left(\mathrm{cm}^{-1}\right)$.

${ }^{g}$ Line strength from HITRAN96 $\left[\mathrm{cm}^{-1} /(\mathrm{atm} \mathrm{cm})\right]$ at $T_{0}=293 \mathrm{~K}$.

${ }^{h}$ Measured line strength $\left[\times 10^{-21} \mathrm{~cm}^{-1} /\left(\right.\right.$ molecule $\left.\left.\mathrm{cm}^{-2}\right)\right]$ at $T_{0}=293 \mathrm{~K}$.

${ }^{i}$ Measured line strength $\left[\mathrm{cm}^{-1} /(\operatorname{atm~cm})\right]$ at $T_{0}=293 \mathrm{~K}$.

${ }^{j}$ Standard deviation of the measured line strength $S_{0, M}\left[\mathrm{~cm}^{-1} /(\mathrm{atm} \mathrm{cm})\right]$.

${ }^{k}$ Difference between the HITRAN96 and the measured line strengths (\%).

Table 2. Comparison of Measured and Published Parameters for the $\mathrm{CO}_{2}$ Transition ${ }^{a}$

\begin{tabular}{cccccc}
\hline$v_{0}\left(\mathrm{~cm}^{-1}\right)$ & Transition & $E^{\prime \prime}\left(\mathrm{cm}^{-1}\right)$ & $S_{0, H}\left[\mathrm{~cm}^{-1} /(\mathrm{atm} \mathrm{cm})\right]$ & $S_{0, M}\left[\mathrm{~cm}^{-1} /(\mathrm{atm} \mathrm{cm})\right]$ & $\Delta S_{0}$ \\
\hline 5007.787 & $R(50)$ & 994.1913 & 0.001268 & 0.001355 & $6.9 \%$ \\
\hline
\end{tabular}

${ }^{a}$ References 5 and 12 . 


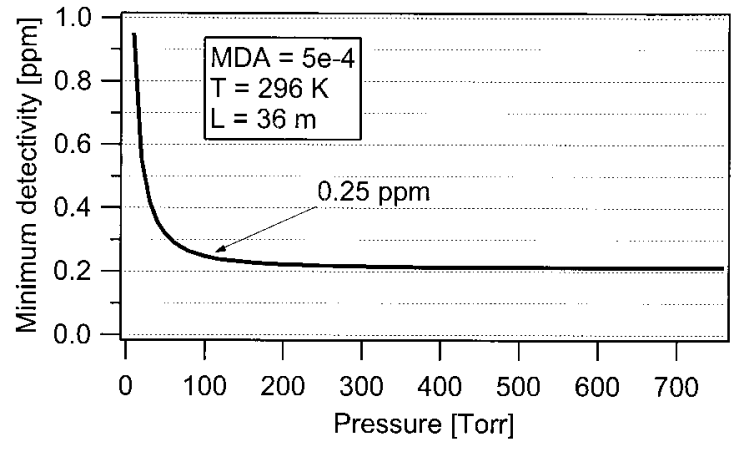

Fig. 8. Predicted minimum detectable mole fraction by use of peak absorption calculations for the $\mathrm{NH}_{3}$ feature at $5016.977 \mathrm{~cm}^{-1}$ for varying pressure conditions. MDA, minimum detectable absorbance.

tinguish absorption signals from background noise. At lower pressures, the population of $\mathrm{NH}_{3}$ molecules decreases, giving less overall signal. The minimum detectivity at 100 Torr and $296 \mathrm{~K}$ is roughly $0.25 \mathrm{ppm}$ for $\mathrm{NH}_{3}$ at $5016.977 \mathrm{~cm}^{-1}$ and 40 ppm for the $\mathrm{CO}_{2}$ transition at $5007.787 \mathrm{~cm}^{-1}$ (assuming a minimum detectable absorbance of $5 \times$ $10^{-4}$, limited by the presence of interference fringes in the multipass cell).

\section{NASA Bioreactor}

NASA's advanced WRS is comprised of the feed tank (or waste tank) that holds the wastewater with high total organic carbon (TOC) and ammonium concentrations, the biological waste processor (BWP), and a postprocessing system, as depicted in Fig. 9 (see Refs. 2 and 1 for a detailed description of the bioreactor). The objectives of the bioreactor are the removal of TOC and nitrification of $\mathrm{NH}_{3}$ as the critical first steps for safe potable $\mathrm{H}_{2} \mathrm{O}$ recovery. In the process of cleaning the wastewater, gaseous $\mathrm{N}_{2}, \mathrm{CO}_{2}$, and trace amounts of $\mathrm{NH}_{3}$ are produced. Aboard spacecraft, these gases will be vented into the cabin and thus might adversely affect the indoor air quality because of potentially toxic levels of $\mathrm{NH}_{3}$. NASA is interested in monitoring $\mathrm{NH}_{3}$ during the ground tests to assess the risks associated with venting the bioreactor gases into the cabin. $\mathrm{CO}_{2}$ measurements for the ground tests are valuable as a rough indicator of the packed-bed reactor's overall health, for which $\mathrm{CO}_{2}$ concentration is approximately related to the reactor's ability to convert wastewater TOC to bacteria and can be used to track carbon balances.

The vent gases were primarily composed of trace $\mathrm{NH}_{3}$ (single-digit ppm or lower), $\mathrm{CO}_{2}$ (500 ppm to $10 \%), \mathrm{N}_{2}$, and saturated water vapor. The sensor design needs to record trace $\mathrm{NH}_{3}$ and varying mole

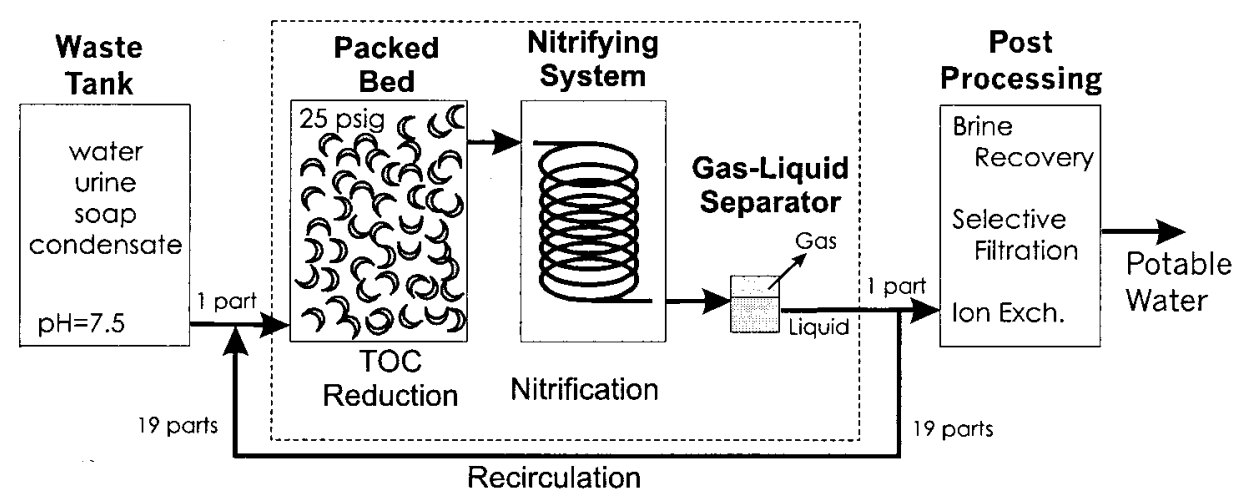

Fig. 9. Schematic of the NASA advanced WRS for water processing aboard spacecraft. The BWP includes the equipment within the dashed rectangle. psig, pounds per square inch (gauge).

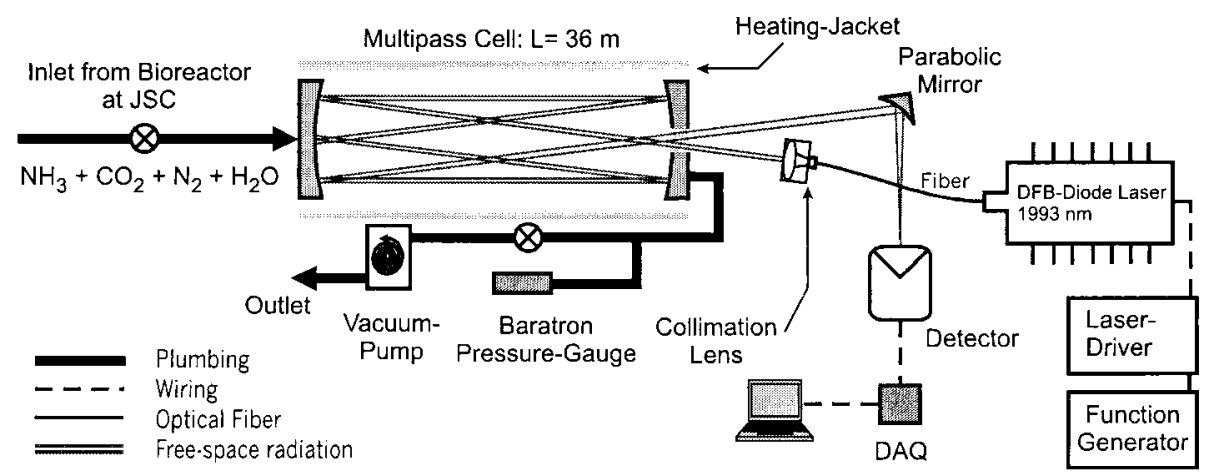

Fig. 10. Schematic of the sensor system to monitor bioreactor vent gases. DAQ, data acquisition. 
fractions of $\mathrm{CO}_{2}$ over extended measurement periods to assess the changes in concentration as a result of different bioreactor conditions.

\section{Experimental Setup}

The experimental schematic for the sensor system developed by Rice University is shown in Fig. 10 (see Claps et al. ${ }^{2}$ for a thorough description). A $5-\mathrm{m}$ polypropylene vent line from the gas-liquid separator in the BWP brought bioreactor vent gases to the Rice sensor system at a flow rate between 10 and $50 \mathrm{~cm}^{3}$ / min, yielding gas transport times from the vent to the multipass cell between 3 and 15 min. A water trap midway through the sampling line allowed for any condensate to be separated from the gases, leaving the $\mathrm{N}_{2}, \mathrm{CO}_{2}, \mathrm{NH}_{3}$, and remaining water vapor to be transported to the sensor.

The sensor was comprised of a 0.3-1 multipass cell with 36-m optical path length and gas residence times between 6 and $30 \mathrm{~min}$. Valves at the entry and exit of the cell in combination with a miniature vacuum pump controlled the cell pressure and flow rate. An operational pressure of 100 Torr was implemented for optimum $\mathrm{NH}_{3}$ detectivity, as determined from Fig. 8. An MKS Baratron pressure gauge monitored the cell pressure at all times. A heat jacket was wrapped around the cell and operated at a steady temperature of approximately $38^{\circ} \mathrm{C}$, as monitored with two thermocouples at each end of the cell. This operational temperature was selected because it is hot enough to prevent water condensation on the walls and mirrors in the cell, but low enough to prevent thermal damage to the cell's seals and optical components and to prevent significant reduction in line strength.

Radiation from a fiber-pigtailed distributedfeedback (DFB) diode laser operating at $1993 \mathrm{~nm}$ for $\mathrm{NH}_{3}$ measurements and $1997 \mathrm{~nm}$ for $\mathrm{CO}_{2}$ measurements was coupled into the multipass cell for a $36-\mathrm{m}$ alignment, then focused onto an extendedwavelength response InGaAs detector by use of a parabolic mirror. The detector used a battery power supply to reduce electrical noise and was connected directly to the data-acquisition system of a laptop computer. The laptop computer collected spectra once per minute during the data collection window. The diode laser was scanned at a $125-\mathrm{Hz}$ repetition rate continuously, and data were sampled at a frequency of $87,500 \mathrm{~Hz}$ to provide 500 data points/ sweep. We used 1000 consecutive averages to reduce electrical noise for $\mathrm{NH}_{3}$ detection, yielding an overall measurement time of $8 \mathrm{~s} ; 500$ averages were used to detect $\mathrm{CO}_{2}$, yielding a 4-s measurement time.

\section{Bioreactor Measurements}

\section{A. 2- $\mu \mathrm{m}$ Diode-Laser Sensor Results}

Using the Rice sensor system and $2-\mu \mathrm{m}$ detection, we made measurements of $\mathrm{NH}_{3}$ and $\mathrm{CO}_{2}$ concentration over a 45-h period at NASA JSC, starting near 9:00 Central Daylight Time (CDT) on 30 August 2000 and ending near 6:00 CDT on 1 September 2000. Sam-

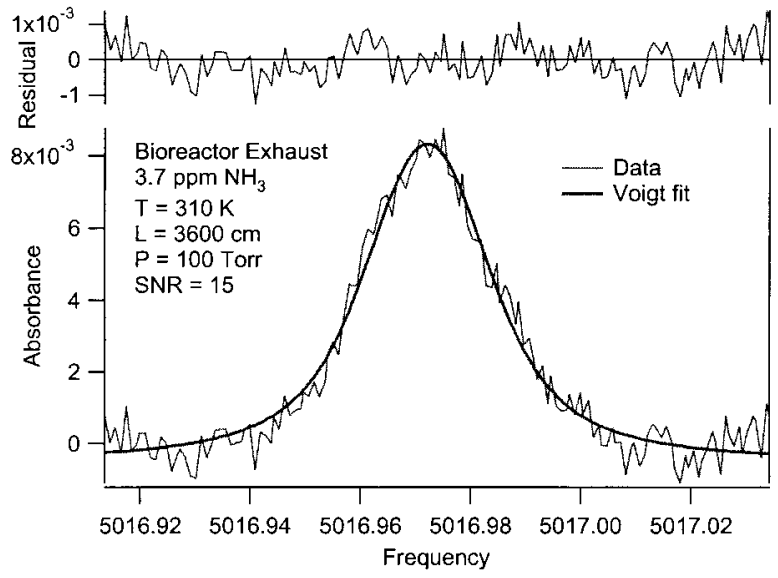

Fig. 11. Sample measurement of 3.7-ppm $\mathrm{NH}_{3}$ in the bioreactor vent gases. SNR, signal-to-noise ratio.

ple measurements of $\mathrm{NH}_{3}$ and $\mathrm{CO}_{2}$ concentration are illustrated in Figs. 11 and 12, respectively. For the first $23 \mathrm{~h}$, measurements of $\mathrm{NH}_{3}$ concentration were made every minute (see Fig. 13), with the exception of one 2.5 -h and one 6 -h window during which the sensor software locked up. The $23 \mathrm{~h}$ of $\mathrm{NH}_{3}$ measurements were followed by $6 \mathrm{~h}$ of $\mathrm{CO}_{2}$ measurements, with one small window during which adjustments to the software were made. $\mathrm{NH}_{3}$ monitoring resumed for another $16 \mathrm{~h}$ after the $\mathrm{CO}_{2}$ collection time ended.

Figure 13 reveals the sensor's ability to operate successfully for automated long-term and remote monitoring of sampled gases. The laser demonstrated little frequency drift or power variation and operated reliably over the 45 -h measurement window, during which it scanned continuously. The concentration trends in Fig. 13 show the sensor's capacity to track bioreactor events. Three of these events are listed on the plot at the time of occurrence. First, the bioreactor was switched into a recycle mode at 14:00 CDT on the first measurement day, during which fresh samples of wastewater were not added to the system. Approximately $4 \mathrm{~h}$ later, the $\mathrm{NH}_{3}$ con-

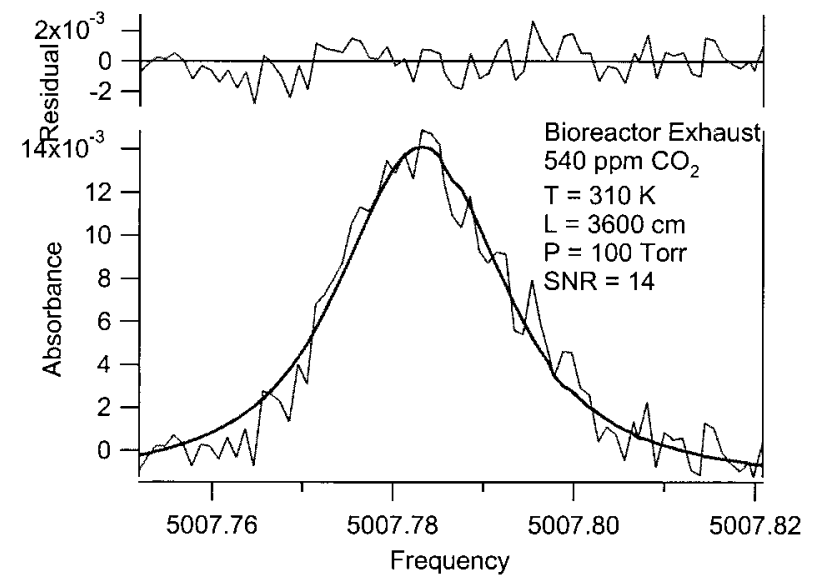

Fig. 12. Sample measurement of 540-ppm $\mathrm{CO}_{2}$ in the bioreactor vent gases. SNR, signal-to-noise ratio. 


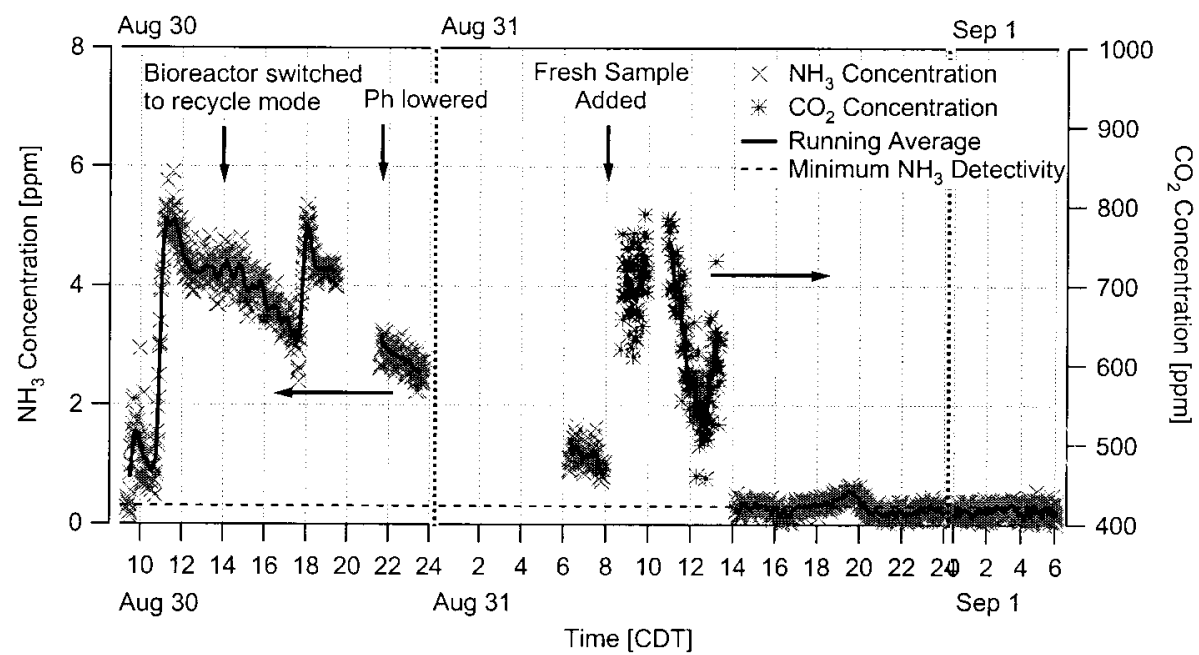

Fig. 13. Concentration measurements of $\mathrm{CO}_{2}$ and $\mathrm{NH}_{3}$ versus time over a 45 -h period.

centration began a steady decline. At approximately 21:00 CDT, nitric acid was added to lower the $\mathrm{pH}$ of the bioreactor and thereby reduce $\mathrm{NH}_{3}$ concentration. The $\mathrm{NH}_{3}$ concentration in the vent gases continues to drop, but whether that drop is due to the lower $\mathrm{pH}$, the recycling, or both is difficult to discern.

At 8:00 CDT on the second measurement day, a fresh 1-1 sample of wastewater was added to the bioreactor to replace a sample that was removed for analysis. The $\mathrm{CO}_{2}$ measurements indicate a slight rise in concentration within $2 \mathrm{~h}$ of that sample addition, which is consistent with the increased TOC conversion under way in the BWP. The resumed $\mathrm{NH}_{3}$ measurements at 14:00 CDT on the second day show $\mathrm{NH}_{3}$ concentration at the limit of detectability, indicating that $\mathrm{NH}_{3}$ levels continued to drop during the $\mathrm{CO}_{2}$ measurement window.

From the bioreactor test data, we infer that the $\mathrm{NH}_{3}$ sensor is quite stable. With the long residence time of sample fluids in the water recovery system, bioreactor events produce variation in the vent gases with a time constant of several hours. Gas residence times for the multipass cell are between 6 and $30 \mathrm{~min}$, as described above. Thus variations over shorter time frames are indicative of sensor performance. Figure 14 shows the $\mathrm{NH}_{3}$ mole fraction measurements over a 1-h period on 30 August 2000, with statistical variations about a mean of $4.2 \mathrm{ppm}$. Overlaid on the minute-by-minute measurements is a 15-min running average, which is half the gas residence time for the slowest flow rates that were used. The typical variation from one measurement to the next is $3 \%$, whereas the largest variation is less than $7 \%$. The standard deviation of the measurements over this hour is $0.1 \mathrm{ppm}$. Thus we conclude that oscillations in measured $\mathrm{NH}_{3}$ mole fraction between 1 and $6 \mathrm{ppm}$ during the first day of data collection are the result of real variations in the gas contents rather than from drift in the sensor system.

The noise-equivalent ammonia detectivity for this system, when only direct absorption is used, is ap- proximately $0.25 \mathrm{ppm}$, as determined by the magnitude of the residuals to the Voigt fits. In comparison, companion measurements made with diode lasers near $1531 \mathrm{~nm}$ by Claps et al. ${ }^{2}$ (see Subsection 7.B) achieved a detectivity of $0.2 \mathrm{ppm}$. Claps et al.'s comparable results were accomplished by use of the same sensor system and with weaker absorption transitions because a balanced detection scheme was implemented. Previously published research with Fabry-Perot diode lasers near $2 \mu \mathrm{m}$ (at $1951 \mathrm{~nm})^{13}$ achieved $3 \mathrm{ppm} / \mathrm{m}$ detectivity (approximately 0.08 ppm if extrapolated to a 36-m path length) with weaker transitions by use of wavelength modulation spectroscopy and second-harmonic detection, although this sensitivity was not demonstrated in the presence of interfering species $\mathrm{H}_{2} \mathrm{O}$ and $\mathrm{CO}_{2}$. When wavelength modulation-spectroscopy or balanced detection strategies are used instead of direct absorption as was used for this study, the detection limits achieved with the ammonia line at $5016.977 \mathrm{~cm}^{-1}$ can most likely be improved by a factor of 5 or better.

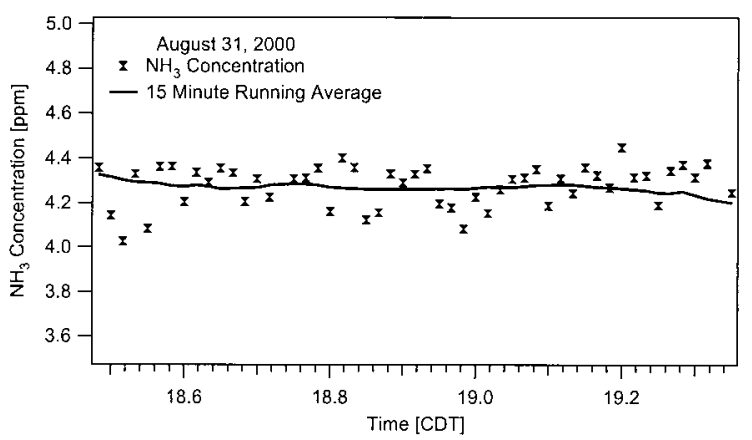

Fig. 14. $\mathrm{NH}_{3}$ mole fraction records over a 1-h period overlaid with a 15-min running average that corresponds to half the gas residence time in the cell. The standard deviation of the measurements during this period is less than $0.1 \mathrm{ppm}$. 
Table 3. Aqueous-Phase Measurements of $\mathrm{NH}_{3}$ Concentration in the Bioreactor and their Corresponding Equilibrium Gas-Phase $\mathrm{NH}_{3}$ Concentrations ${ }^{a}$

\begin{tabular}{ccc}
\hline Date & $\mathrm{NH}_{3}(\mathrm{Aq})(\mathrm{mg} / \mathrm{l})$ & $X_{\mathrm{NH}_{3}}(\mathrm{ppm})$ \\
\hline 29 Aug. & 20.7 & 8.3 \\
30 Aug. & 19.9 & 8.0 \\
31 Aug. & 10 & 4.0 \\
1 Sept. & 14.5 & 5.8 \\
2 Sept. & 6.1 & 2.4 \\
\hline
\end{tabular}

${ }^{a} T=291 \mathrm{~K}, P=25$ psi (gauge).

\section{B. Comparison Measurements}

\section{1.5-um Diode-Laser Sensor Measurements}

Measurements with diode-laser sensors at $1531 \mathrm{~nm}$ were performed in the days prior and subsequent to the results in this study and are presented by Claps et al. ${ }^{2}$ The measurements made with lasers near 1.5 $\mu \mathrm{m}$ were not made simultaneously with the $2.0-\mu \mathrm{m}$ measurements presented here; thus a direct comparison cannot be made. However, the results from the shorter-wavelength measurements do provide a rough estimate for the order-of-magnitude concentrations that could be expected in the vent gases. For several days before the beginning of the $2.0-\mu \mathrm{m}$ detection and for one week thereafter, the $\mathrm{NH}_{3}$ concentrations in the bioreactor vent gases oscillated between 0 and $5.6 \mathrm{ppm}$. A similar oscillation is evident in Fig. 13 on 20 August Day between 10:00 and 18:00 CDT. The remainder of the $\mathrm{NH}_{3}$ data in this study are dominated by the switch of the reactor to the recycle mode and the change in $\mathrm{pH}$. The subsequent Rice data beginning 1 September show similarly low concentrations of $\mathrm{NH}_{3}$ mole fraction before the bioreactor was switched on again and the oscillations in $\mathrm{NH}_{3}$ mole fraction resumed. That the results of the 2 - $\mu \mathrm{m}$ laser sensor smoothly fit the overall time sequence of Rice data further suggests comparable sensor performance.

\section{Aqueous-Phase Measurements}

In addition to the $1.5-\mu \mathrm{m}$ diode-laser results, measurements of aqueous ammonia concentrations in the packed-bed reactor were made once daily by the advanced WRS research team at NASA JSC in the mornings using standard wet-chemistry techniques. These concentrations, in units of milligrams per liter, can be converted to gas-phase equilibrium concentrations by use of Henry's law. ${ }^{14}$ Table 3 summarizes the values for the days of the measurements in addition to one preceding day and one following day. Because these measurements were made at one instant in the day and in the packed-bed reactor, they serve as only a rough indicator of the order-of-magnitude concentration that can be expected in the bioreactor vent gases. These mole fractions varied from nearly $8.3 \mathrm{ppm}$ down to $2.4 \mathrm{ppm}$ over the five-day period including the measurement window. A distinct reduction in $\mathrm{NH}_{3}$ concentration from $8.0 \mathrm{ppm}$ on 30 August 2000 to 4.0 ppm on 31 August 2000 is consistent with the results from the Stanford diode-laser sensor, which shows a diminishing $\mathrm{NH}_{3}$ population in the vent gases beginning at 18:00 CDT on 30 August and continuing through midday 31 August.

\section{Conclusions}

Sensors were designed for detection of trace $\mathrm{NH}_{3}$ and varying concentrations of $\mathrm{CO}_{2}$ in the vent gases of a bioreactor. A DFB laser operating near $2 \mu \mathrm{m}$ offered significant gains in accessible absorption intensities, so the optimum transitions in that region were selected for use with an automated and portable sensor system developed at Rice University. The Rice sensor system employed a multipass cell, which increased sensitivities and allowed for low-pressure operation to isolate the different absorption transitions, and direct absorption. We adapted the sensor system for operation at $2 \mu \mathrm{m}$ by changing the laser and the detector and operating it over a 45-h period for quasi-continuous measurements of $\mathrm{NH}_{3}$ and $\mathrm{CO}_{2}$ concentration. A detection limit of 0.25-ppm $\mathrm{NH}_{3}$ and 40-ppm $\mathrm{CO}_{2}$ was demonstrated. Measurements of $\mathrm{NH}_{3}$ concentration agreed roughly with values recorded by a $1.5-\mu \mathrm{m}$ system in the days preceding and following the $2-\mu \mathrm{m}$ measurements and with oncedaily aqueous-phase measurements of ammonia. Trends in $\mathrm{NH}_{3}$ and $\mathrm{CO}_{2}$ concentration were consistent with different bioreactor events during the measurement period.

The research at Stanford University was sponsored by the U.S. Environmental Protection Agency's Office of Research and Development's National Center for Environmental Research Science to Achieve Results research grants program. The research at Rice University and NASA JSC was sponsored by NASA JSC and the Texas Advanced Technology Program. M. E. Webber thanks the Laser Science group at Rice for their hospitality as hosts for the measurements at NASA JSC. M. E. Webber, R. Claps, and F. V. Englich express their gratitude to NASA JSC's Crew and Thermal Systems Division personnel for giving the necessary logistics support to the experiment. We thank Yuji Ikeda at Kobe University for supplying the 2.0- $\mu \mathrm{m}$ laser.

\section{References}

1. G. M. Kirby, "Advanced water recovery system (WRS) integrated test plan,” Tech. Rep. JSC 39893 (NASA Lyndon B. Johnson Space Center, Houston, Tex., 2000).

2. R. Claps, F. V. Englich, D. P. Leleux, D. Richter, F. K. Tittel, and R. F. Curl, "Ammonia detection by use of near-infrared diode-laser-based overtone spectroscopy," Appl. Opt. 40, 43964403 (2001).

3. V. Nagali, S. I. Chou, D. S. Baer, R. K. Hanson, and J. Segall, "Tunable diode-laser absorption measurements of methane at elevated temperatures," Appl. Opt. 35, 4026-4032 (1996). 
4. M. E. Webber, D. S. Baer, and R. K. Hanson, "Ammonia monitoring near $1.5 \mu \mathrm{m}$ with diode laser absorption sensors," Appl. Opt. 40, 2031-2042 (2001).

5. L. S. Rothman, C. P. Rinsland, A. Goldman, S. T. Massie, D. P. Edwards, J.-M. Flaud, A. Perrin, C. Camy-Peyret, V. Dana, J.-Y. Mandin, J. Schroeder, A. McCann, R. R. Gamache, R. B. Wattson, K. Yoshino, K. V. Chance, K. W. Jucks, L. R. Brown, V. Nemtchinov, and P. Varanasi, "The HITRAN molecular spectroscopic database and HAWKS (HITRAN atmospheric workstation): 1996 edition,” J. Quant. Spectrosc. Radiat. Transfer 60, 665-710 (1998).

6. L. Lundsberg-Nielsen, F. Hegelund, and F. M. Nicolaisen, "Analysis of the high-resolution spectrum of ammonia $\left({ }^{14} \mathrm{NH}_{3}\right)$ in the near-infrared region, 6400-6900 $\mathrm{cm}^{-1}$," J. Mol. Spectrosc. 162, 230-245 (1993).

7. L. Lundsberg-Nielsen, "Molecular overtone spectroscopy on ammonia," Ph.D. dissertation (Department of Chemistry, University of Copenhagen, Danish Institute of Fundamental Metrology, Copenhagen, Denmark, 1995).

8. R. M. Mihalcea, M. E. Webber, D. S. Baer, R. K. Hanson, G. S. Feller, and W. B. Chapman, "Diode-laser absorption measure- ments $\mathrm{CO}_{2}, \mathrm{H}_{2} \mathrm{O}, \mathrm{N}_{2} \mathrm{O}$, and $\mathrm{NH}_{3}$ near $2.0 \mu \mathrm{m}$," Appl. Phys. B 67, 283-288 (1998).

9. L. R. Brown and J. S. Margolis, "Empirical line parameters of $\mathrm{NH}_{3}$ from 4791 to $5294 \mathrm{~cm}^{-1}$," J. Quant. Spectrosc. Radiat. Transfer 56(2), 283-294 (1996).

10. S. Sarangi, "Analysis of the $v_{3}+v_{4}$ band of ammonia," J. Quant. Spectrosc. Radiat. Transfer 18, 257-288 (1977).

11. S. Sarangi, "Analysis of line intensities in the two-micron band of ammonia," J. Quant. Spectrosc. Radiat. Transfer 18, 289293 (1977).

12. M. E. Webber, S. Kim, S. T. Sanders, D. S. Baer, R. K. Hanson, and Y. Ikeda, "In situ combustion measurements of $\mathrm{CO}_{2}$ near $2.0 \mu \mathrm{m}$ by use of a distributed feedback diode-laser sensor," Appl. Opt. 40, 821-828 (2001).

13. L. Sandström, S. Bäckström, H. Ahlberg, S. Höjer, and A. G. Larson, "Gas monitoring using semiconductor lasers operating in the $2 \mu \mathrm{m}$ wavelength region," Infrared Phys. Technol. 39, 69-75 (1998).

14. J. H. Seinfeld and S. N. Pandis, Atmospheric Chemistry and Physics: From Air Pollution to Climate Change (Wiley, New York, 1998). 